\title{
Los parlamentarios de los territorios vasco-navarros y la discusión de la Constitución republicana de 1931
}

\author{
José Maria Gill Angulo
}

En la vida de una sociedad democrática, el dotarse de una serie de leyes que regulen las pautas de convivencia de sus miembros es determinante para caracterizar el día a día de ese colectivo. La Constitución como conjunto de normas reguladoras de tal convivencia tendría esa función. En consecuencia, la tendencia que tomen esas normas será fundarnental para la vida del ciudadano. Ello implica que su redacción debe recoger aquellos principios que mayoritariamente caracterizan a sus destinatarios, pero a la vez contener el derecho a la expresión de las ideas de los grupos minoritarios de cada momento. En el caso que aquí nos ocupa, la implantación de la Segunda República en España, ésta supuso tener que modificar el conjunto del ordenamiento social, político, religioso, etc. que había regido en la sociedad española hasta ese momento. La llegada de la República trajo consigo la democracia, una democracia incipiente pero que permitía a los españoles ejercer su derecho al voto en elecciones a las que podian concurrir partidos políticos de las mas diversas ideologias. De esta manera la experiencia republicana supuso el acceso de las masas a la politica, la cual iba a ocupar un lugar importante en las vidas de buena parte de los españoles .

En palabras de Santiago Varela: "Simplificando, puede realizarse una primera aproximación a la cuestión de cambio político, afirmando que el régimen parlamentario-oligárquico de la Restauración fue sustituido en 1931. tras el paréntesis de la dictadura, por un régimen parlamentario democrático, dando lugar a un súbito e intenso proceso de politización que afectaria a amplios sectores de la sociedad española" (VARELA DiAz, S. Partidos y Parlamento en la segunda república española. Fundación Juan March, Madrid, 1978, pág. 24) y poco más adelante (pág. 25) concluye que el acceso de las masas al protagonismo politico "fue el rasgo mas sobresaliente de la Segunda República comparada con la situación política anterior». 
Con estas premisas no es de extrañar que uno de los primeros objetivos del Gobierno provisional surgido tras la proclamación de la República el 14 de abril de 1931 y bajo la presidencia de Niceto Alcalá-Zamora fuera crear un marco jurídico que permitiese la convocatoria de unas elecciones para Cortes Constituyentes. Ante estas elecciones el País Vasco junto a Cataluña eran los únicos territorios con sistema propio de partidos y no subsistemas regionales? Como notas características del territorio vasco, citar la existencia de un partido nacionalista fuerte, el Partido Nacionalista Vasco (PNV). Junto a él, las fuerzas tradicionalistas o carlistas ${ }^{3}$ y un tercer movimiento formado por las izquierdas republicanas y socialistas.

Un decreto de 3 de junio de $1931^{4}$ firmado por todo el Gobierno Provisional de la República, convocaba las elecciones a Cortes Constituyentes las cuales se celebrarian el 28 de junio de 1931, reguladas por la "Ley electoral para diputados a Cortes y concejales de 8 de agosto de 1907", con las modificaciones que supuso la aplicación del "Decreto de 8 de mayo de 1931" del Gobierno provisional de AlcaláZamora, encaminado según su preámbulo a corregir las prácticas caciquiles imperantes en España y para ello el nuevo decreto establecía las circunscripciones provinciales, más difíciles de controlar por los caciques rurales y el mejor sistema para colocar "en plano de igualdad a todos los electores y elegibles..." ${ }^{5}$. Se dio una participación nunca vista hasta la fecha, 4.348.691 españoles acudieron a votar, lo que equivalía al 70,14 por ciento del censo electoral, es decir, un $3 \%$ más que en las municipales del 12 de abril. Mediante el sufragio universal masculino, la Conjunción republicano-socialista consiguió el máximo de diputados ${ }^{6}$.

\footnotetext{
Granja, José Luis de la,: República y Guerra Civil en Euskadi, (del pacto de San Sebastián al de Santoña), IVAP, Oñati, 1990, pág. 91.

3 Como señala Ferrer Muñoz, la llegada del régimen republicano supuso un revulsivo para que el carlismo recuperara su unidad mediante el retorno de los mellistas (o tradicionalistas) e integristas a la disciplina del partido, desembocando en la Comunión Tradicionalista, en la que al menos teóricamente dejaban de ser perceptibles las direrencias sectoriales que en la historia, entonces casi centenaria, del carlismo habían minado su fuerza. La proclamación de la República y el posterior fallecimiento de don Jaime, $\in$ n octubre de 1931 habrian de ser elementos decisivos para el logro de la reconciliación de los meillistas. FERRER MUÑOz, Manuel. Elecciones y Partidos Políticos en Navarra durante la segunda República. Gobierno de Navarra. Departamento de Educación y Cultura. Pamplona, 1992, págs .101-102.

4 GACETA, del 4 de junio de 1931.

5 LEY electoral vigente para diputados a Cortes y concejales. Gráfica Socialista. Madrid, 1933, pág. 41

6 Gill Pecharroman, Julio: La Segunda República. Esperanzas y frustraciones. Historia 16 Ediciones Temas de Hoy, Madrid, 1996.
} 
Por lo que hace referencia a los resultados en el País Vasco, éstos fueron claros. Habia triunfado la candidatura nacionalista-católica-carlista. De los 24 diputados elegidos, 15 lo fueron para esta coalición (8 nacionalistas, 5 carlistas y 3 católicos independientes), repartidos en lo geográfico 5 por Vizcaya y Navarra, 4 por Guipúzcoa, y 1 por Alava, mientras la coalición republicano-socialista obtuvo 9 diputados $(6$ republicanos y 3 socialistas) con una distribución de 4 por Vizcaya, 2 por Navarra y Guipúzcoa y 1 por Álava.

REPUBLICANOS-SOCIALISTAS

\begin{tabular}{ccr}
\hline PROVINCIA & DIPUTADOS & VOTOS \\
\hline ALAVA & SUSAETA & 8.513 \\
GUIPUZCOA & USABIAGA & 25.928 \\
GUIPUZCOA & DE FRANCISCO & 25.612 \\
NAVARRA & ANSO & 27.181 \\
NAVARRA & AZAROLA & 27.045 \\
VIZCAYA CAPITAL & PRIETO & 32.982 \\
VIZCAYA CAPITAL & ARAQUISTAIN & 32.316 \\
VIZCAYA CAPITAL & ALDASORO & 31.961 \\
VIZCAYA CAPITAL & FATRAS & 31.702 \\
\hline
\end{tabular}

GRUPO MINORÍA VASCO-NAVARRA

\begin{tabular}{ccc}
\hline PROVINCIA & DIPUTADOS & VOTOS \\
\hline ALAVA & ORIOL & 8.016 \\
GUIPUZCOA & PILDAIN & 35.942 \\
GUIPUZCOA & PICAVEA & 35.937 \\
GUIPUZCOA & LEIZAOLA & 35.901 \\
GUIPUZCOA & URQUIJO & 35.819 \\
NAVARRA & GORTARI & 46.325 \\
NAVARRA & AIZPUN & 46.699 \\
NAVARRA & AGUIRRE & 46.419 \\
NAVARRA & BEUNZA & 46.102 \\
NAVARRA & DOMINGUEZ AREV & 45.940 \\
VIZCAYA CAPITAL & HORN & 23.540 \\
VIZCAYA CAPITAL & EGUILEOR & 23.319 \\
VIZCAYA PROVINCIA & OREJA & 15.982 \\
VIZCAYA PROVINCIA & BASTERRECHEA & 14.601 \\
VIZCAYA PROVINCIA & ROBLES (7) & 19.527 \\
\hline
\end{tabular}


Como peculiaridad, señala el profesor de la Granja, el País Vasco fue la única de las regiones y nacionalidades peninsulares donde no vencieron los republicanos y socialistas, sino una unión de derechas, sin parangón en el resto del Estado ?. Con lo que haciendo uso de la "teoría del oasis" ${ }^{8}$, el País Vasco se convertía en una especie de oasis católico y conservador frente a una España laica en proceso de revolución democrático-burguesa.

\section{EL DEBATE DE LA CONSTITUCIÓN}

Entre el 14 de julio de 1931, fecha de apertura de las Cortes que eligieron a Julián Besteiro como presidente y el 9 de diciembre de 1931 fecha de la aprobación del texto definitivo, se procedió a redactar y a discutir una nueva Constitución para el país.

Rechazado por los representantes de la izquierda el primer anteproyecto, el Gobierno encomendó la redacción de otro a una Comisión parlamentaria nombrada en la sesión del día 28 de julio de 1931, en la que se reflejaba la proporcionalidad de las diversas minorías parlamentarias, apreciándose en su composición la importante presencia de los territorios vasco-navarros por medio de dos socialistas Luis Araquistain (Vizcaya capital) y Enrique de Francisco (Guipúzcoa) y un nacionalista Jesús $M{ }^{a}$ de Leizaola ${ }^{9}$. Los trabajos para la elaboración del proyecto constitucional se iniciaron el 29 de julio y acuciados por las presiones y urgencias del Gobierno, tan sólo veinte días después, el 18 de agosto de 1931, fue presentado a las Cortes un proyecto que estaba compuesto por 121 artículos comprendidos en 19 títulos, redactados por los cinco miembros socialistas de la Comisión, en base - con modificaciones esenciales- al anteproyecto de la Comisión Jurídica Asesora, y luego discutidos con los demás representantes. La discusión parlamentaria se extendió a lo largo de tres meses y doce días, desde el 27 de agosto al 9 de diciembre de 1931, fecha en lá que se sometió a votación el conjunto del articulado quedando aprobado con 368 votos a favor, 89 ausencias y ningún pronunciamiento en contra ${ }^{10}$.

Granja Sainz, J. L. op. cit., pág. 20.

8 El catalán Mañé y Flaquer escribió un libro titulado significativamente El oasis. Viaje al pais de los Fueros (1878-1880).

9 Sustituto de José Horn desde el dia 31 de julio.

10 Tamames, Ramón : La Repúbiica. La era de Franco. Alianza Editorial. Alfaguara. Madrid, pág. 159. 
El discurso del Presidente de la Comisión Constitucional, Jiménez de Asúa, pronunciado en la sesión del 27 de agosto, inició el debate constitucional, estando las primeras sesiones dedicadas a la discusión "a la totalidad» del proyecto, para en días posteriores pasar a la discusión sistemática del nuevo texto comenzando por el artículo referente a la organización del Estado. Los debates sirvieron para clarificar las posiciones de los grupos políticos ante los grandes temas de la vida nacional. Entre los grupos parlamentarios se manifestaron actitudes dispares respecto al espíritu de la Carta. Socialistas y radical-socialistas ponian especial énfasis en los contenidos de reforma social, así como en el recorte de los privilegios de las oligarquías tradicionales y de la Iglesia. Los partidos de la Alianza Republicana querian un texto que pudiera ser suscrito por todos los grupos de la coalición gobernante, que cubría un amplio espectro ideológico. Sin embargo conforme avanzaban los debates, Acción Republicana (AR), el partido de Azaña, aumentaría su aproximación a las tesis socialistas, mientras los radicales se orientaban resueltamente hacia el centro político. Los grupos nacionalistas, y en especial los catalanistas, buscaban en la Constitución un marco legal de autogobierno para sus territorios; pero en otras cuestiones, las diferencias entre los nacionalistas y los conservadores del Partido Nacionalista Vasco y de la Liga eran abismales. Los radicales y los intelectuales de la Agrupación al Servicio de la República representaban una minoritaria postura de centro-derecha, empeñada en buscar formulas de conciliación que salvaguardasen bajo una República liberal y unitaria, el orden socioeconómico vigente. Finalmente, la derecha republicana, anclada en posiciones abiertamente reaccionarias e intransigentes, se opuso a la totalidad del programa reformista de la Conjunción republicano-socialista.

Posicionamiento de los diputados vasco-navarros ante el proyecto de Constitución

Jesús M. ${ }^{a}$ de Leizaola Sánchez, diputado nacionalista por la Minoría vasco-navarra, expuso los criterios que marcarian a este grupo y que servirian como referente para lo que sería desarrollado por sus compañeros en sucesivas intervenciones con motivo de la discusión de la nueva Constitución. Una de las ideas principales asumidas tanto por él como por los suyos, fue el rechazo, la hostilidad de buena parte de la Cámara hacia las actitudes e ideologia que representaba el grupo Minoría V-N. 
Enemistades que no eran fortuitas, ya que esta oposición -lógica por otra parte en la estrategia parlamentaria - respondía a la actitud declarada de la M.V-N. Ello no obstó para que el orador hiciese la siguiente reflexión:

"por primera vez en la historia constitucional se pude decir que en unas Cortes se encuentra presente la integridad de la representación política del pueblo vasco" "'.

$Y$ aunque la afirmación no es cierta al $100 \%$ ya que faltaban algunos grupos como los comunistas, Acción Nacionalista Vasca, etc. lo que no se puede negar es que el abanico de pensamientos políticos de los territorios vasco-navarros era de una amplitud notable.

Como señala el profesor de la Granja ${ }^{12}$, desde 1904 la meta del PNV venía siendo la derogacion de la ley de 25 de octubre de 1839, es decir, la plena restauración de los Fueros, de donde arrancaría la reiterada indeterminación del citado partido sobre el objetivo de la independencia, pues para unos la reintegración foral era sinónimo de independencia mientras que para otros no. En el caso del texto constitucional, aún reconociendo que hubiese sido más de su agrado un planteamiento federalista y una terminología de "Estado", no ataca la denominación adoptada de uregión autónoma".

Junto al tema político, el religioso no podía faltar en esta valoración. Como es de suponer, el orador defendió la peculiaridad religiosa del País Vasco, su tradicional catolicismo, frente a la corriente antirreligiosa que impregnaba mayoritariamente el espíritu de la Cámara. Esta discrepancia con el sentir general la reflejó afirmando "que en el pueblo vasco sigue en pie la voluntad de permanecer fiel a su secular fisonomía espiritual's ${ }^{13}$,

Sobre este tema de los nacionalistas y la religión católica, Aizpuru y Unanue ${ }^{14}$ defienden que entre el clero vasco la supremacía ideológica la llevaban los tradicionalistas, representados en su mayoría por los sacerdotes de mayor edad, mientras que las nuevas generaciones de clérigos

$11 \quad$ D. de S. n.934 de 8 de septiembre de 1931, pág. 791.

12 Granja, J.L. de la: "El nacionalismo vasco entre la autonomia y la independencia", en Los nacionalismos en la España de la /l República. Siglo XXI editores, Madrid, 1991, pág. 103

13 D. de S. n. 34 de 8 de septiembre de 1931, pág. 793.

14 AizPuRu, Mikel Xabier y UnANuE, Donato,: "El clero diocesano y el nacionalismo vasco: un análisis sociológico", en Los nacionalismos en la España republicana. Sigło XXI editores, Madrid, 1991, págs. 287-295. 
se acercaban más a los postulados nacionalistas, ya que vieron en este movimiento el medio más eficaz de impulsar la cultura vasca.

Continuando el repaso de Leizaola a los temas fundamentales que se plasmaban en la nueva Constitución, un asunto que se llevó un espacio importante fue el del derecho y las libertades individuales y sociales: "Yo no estoy conforme con que este texto constitucional ensanche el territorio de las libertades individuales y sociales, [...] porque este texto constitucional cercena entre otras cosas estas libertades, la libertad de enseñanza, la libertad de asociación y el derecho de los padres de familia a dirigir la educación de sus hijos» ${ }^{15}$. Otros argumentos que sirven de base para esta discrepancia son los referidos a temas como el divorcio, la propiedad privada, etc.

Respecto a la forma y funciones de los órganos de gobierno manifestó una idea clara: "al Estado hay que hacerle fuerte» ${ }^{16}$, y en cuanto a otro tema que considera de fundamental importancia, el trabajo, está totalmente de acuerdo conque se elevase su condición con mayores derechos ya que "la Iglesia fue quien dignificó el trabajo" ${ }^{17}$, haciendo énfasis en que en el territorio vasco siempre se habia dado una tradición asociacionista, como las Cofradías, Sindicatos, Seguros, etc. Todo lo anterior respaldado por una contundente afirmación en la que por una parte vemos una muestra de acatamiento del nuevo régimen, algo que estaba en contradicción con el pensamiento de una parte importante de los componentes de su grupo parlamentario: "dada mi significación política, yo soy republicano" 18 .

Por lo que hace referencia al desarrollo sistemático de las discusiones de los diferentes títulos y artículos del proyecto constitucional, en el Título Preliminar (arts. 1 a 7) del proyecto de la Comisión se definía España como un República «democrática», pero el diputado del grupo Radical Socialista, Valera, promovió una enmienda que la definía como «República de los trabajadores" ${ }^{19}$. Esta enmienda sería recogida y defendida por el socialista vizcaíno Luis Araquistain Quevedo en nombre de su grupo parlamentario. Para ello en su intervención amplió el tradicional concepto de trabajador a «toda persona que desempeña una función material o espiri-

\footnotetext{
D. de S. n. ${ }^{0} 34$ de 8 de septiembre de 1931, pág. 794 .

D. de S. n. 34 de 8 de septiembre de 1931, pág. 795 .

D. de S. $n .{ }^{\circ} 34$ de 8 de septiembre de 1931, pág. 796 .

D. de S. n. ${ }^{\circ} 34$ de 8 de septiembre de 1931, pág. 796.

D. de S. n. 938 de 15 de septiembre de 1931.

D. de S. n. 39 de 16 de septiembre de 1931, pág. 941 .
} 
tualmente necesaria a la sociedad donde vive" ${ }^{20}$, es decir, abarcaría prácticamente a todos los miembros de la sociedad, excluyendo únicamente "al ocioso inveterado, al vago de oficio, al parásito social»" ${ }^{21}$, alejando con ello el temor a una dictadura del proletariado, algo a lo que calificó de típico fenómeno ruso. Aprovechó la ocasión para hacer un repaso de los conceptos Estado e individuo y su reflejo en diversas constituciones europeas, en concreto sobre

"la evolución de la idea del Estado y como estamos pasando del Estado individualista subjetivo, at de los derechos absolutos, a un estado de normas» 22.

La enmienda significó el rechazo de Acción Republicana (AR), los radicales y el conjunto de las derechas. Finalmente se llegó a un acuerdo mediante la fórmula "España es una República de trabajadores de toda clase que se organizan en régimen de libertad y de justicia".

Con relación al tema de la lengua (art. 4), y ante los ataques hacia otras lenguas distintas al castellano realizados en su intervención por el diputado Miguel de Unamuno ${ }^{23}$, en el caso concreto de la lengua vasca, Leizaola, si bien reconoció los conocimientos de su colega sobre la situación de la citada lengua en décadas anteriores, mostro su disconformidad sobre los argumentos aportados por el profesor a la situación del momento. Para ello recurrió a la defensa de su lengua vernácula en todos los usos de la vida, tanto familiares como administrativos, y a su reconocimiento por parte de la Administración, acusando a los organismos estatales de utilizarla únicamente para la vía recaudadora. Por otro lado, se muestra de acuierdo con la redacción inicial del proyecto constitucional cuando señala que «el español es el idioma oficial de la República. Todo ciudadano español tiene el deber de saberlo y el derecho de hablarlo". A partir de ahí sin embargo, planteó las discrepancias sobre la redacción que se daba a la situación existente en territorios con más de una lengua de uso habitual, referido a aspectos como pudiera ser la obligatoriedad de su conocimiento para determinados colectivos de servicios públicos. Con ello se refería no solo a los territorios con cierta autonomía legislativa, sino que amplia dicha facultad a todo aquella región caracterizada por po-

21 D. de S. n. ${ }^{\circ} 39$ de 16 de septiembre de 1931, pág. 941.

D. de S. n. ${ }^{\circ} 39$ de 16 de septiembre de 1931, pág. 943.

23 Don Miguel de Unamuno y Jugo se opuso en las Cortes Constituyentes a la concesión de las autonomias regionales, aunque luego, - una paradoja más en su vida- votó a favor del Es tatuto catalán. 
seer un lenguaje propio y diferenciado: "para que en un país que no se constituya jurídicamente como región, pero que tenga Lenguas diversas, los derechos de esas Lenguas, sin necesidad de autonomía regional, sean compatibles con la Constitución" ${ }^{24}$. Los argumentos tendrían su eficacia al comprometerse el Sr. Jiménez de Asua, presidente de la Comisión, a realizar una nueva redacción que pudiera dar satisfacción a las demandas planteadas.

Los títulos Preliminar y Primero se discutieron conjuntamente, y dentro de uno de los tres turnos en contra de los mismos intervino el diputado por Navarra Rafael Aizpún Santafé, católico independiente y ex-maurista, integrado en la Minoría vasco-navarra. Imbuido del ambiente estatutista del momento en algunos territorios, solicitó que dicho título "no cierre las puertas ni a los estatutos ni a ninguna de aquellas peticiones fundamentales o simplemente importantes que los estatutos contengan" ${ }^{25}$.

En definitiva una Constitución flexible y oponiéndose concretamente al artículo 14 que enumeraba las materias de competencia exclusiva del Estado, por suponer un tope al Estatuto vasco, sobre todo en lo referente a las relaciones entre la Iglesia y el Estado - como la competencia para concordar con Roma - que el proyecto vasco reclamaba ${ }^{26}$.

El tema de la organización nacional (arts. 8 a 22) significó la introducción de un nuevo planteamiento en los artículos 11 a 13, donde se reconocía el derecho a que una o varias provincias limítrofes, con características históricas, culturales y económicas comunes, acordaran organizarse en región autónoma, presentando un Estatuto para su discusión en las Cortes. Fue objeto de numerosos votos particulares y enmiendas a través de las cuales se defendian posiciones muy distintas sobre la concepción de la estructura territorial de España. El representante de la Comisión encargado de dar respuesta a los votos particulares fue el diputado vasco Jesús $M^{a}$ de Leizaola Sánchez, quien expuso que el criterio mantenido por la Comisión era reconocer la autonomía a los Municipios y a las Regiones, eliminando la autonomia de la provincia, "que nadie ha defendido" ${ }^{27}$. Algo en cierto modo paradójico ya que tradicionalmente los órganos forales habian sido siempre de ámbito provincial en cuanto a su régimen organizativo, y cuando se comenzó el proceso de elaboración del proyecto estatutario, el límite provincial fue

${ }^{24}$ D. de S. n. 90 de 17 de septiembre de 1931, pág. 1025.

25 D. de S. n. 89 de 10 de septiembre de 1931, pág. 851.

26 D. de $S$. $n .89$ de 10 de septiembre de 1931, págs. 851-853.

${ }^{27}$ D. de S. n. ${ }^{\circ} 42$ de 22 de septiembre de 1931, pág. 1050. 
visto por no pocos nacionalistas vascos como punto de origen para ese proceso. Quizá como desagravio y dada la proximidad de un caso que le afectaba directamente, hizo constar que el carácter de la negación no era absoluto, ya que la provincia, por sí misma, podía pedir la declaración de Región autónoma mediante la aprobación de un Estatuto como era el caso de Navarra. La orientación de la Comisión era ir hacia la Constitución de regiones, dotándolas de autonomía, pero sin cerrar el paso a la posibilidad de que las regiones coincidieran con la provincia. Respecto a las regiones autónomas, afirmó que "Tantas cuantas regiones quieran constituirse tendrán un régimen de autonomía, régimen de autonomía que será igual si ellas, por su iniciativa, 10 quieren igual, y que solo será desigual cuando ellas, por su propia iniciativa, asi lo deseen" ${ }^{28}$.

Entre el 22 y el 27 de septiembre tuvo lugar el debate autonómico originando complejas negociaciones y alianzas de cara a conseguir sacar adelante el texto constitucional. Al contrario que los casos de reforma agraria o el ejército, temas de naturaleza socioeconómica, se trataba de una cuestión de dimensión histórica: la forma de integración de la Nación. La República debia rehacer a España como un sistema de integración unitario, no centralista, según Jiménez Asua, "un Estado integral, en el que sean compatibles, junto a la gran España, las regiones, y haciendo posible, en ese sistema integral, que cada una de las regiones reciba la autonomía que merece por su cultura y progreso". Por lo tanto no se trataba de un pleito regional a resolver por los vascos y catalanes por un lado y el Gobierno central por otro, sino que habría de abarcar en el futuro a todas las regiones. Desgraciadamente las reacciones de los diversos sectores del país no estuvieron, en líneas generales, a la altura de las circunstancias, predominando tanto los espíritus localistas de los regionalistas, como los prejuicios de los españolistas. De esta manera ${ }^{29}$ unos y otros actuaban más como elementos de disociación que de integración. Frente a los regionalistas defensores de altas tasa de autogobierno, la derecha nacional, muchos parlamentarios republicanos, intelectuales y un sector del PSOE consideraban el tema como algo ligado en buena medida a los intereses egoístas de la burguesía local, acusando en el caso catalán a los regionalistas de deslealtad en sus peticiones a lo acordado en el Pacto de San Sebastián.

Los representantes vasco-navarros por su parte veían en el autogobierno una garantía de estabilidad para sus regiones de mayoría católica y

28 D. de S. n. ${ }^{\circ} 42$ de 22 de septiembre de 1931, pág. 1051

29 Bullejos, José: España en la // República. Júcar, Madrid, 1977, pág. 80-81 
conservadora frente al predominio de la izquierda anticlerical en el Gobierno Central.

Con relación al artículo 12, en el que se exigía el voto positivo de las dos terceras partes de los electores inscritos en el censo para dar por aprobado un referéndum, en este caso, el que afecta a la aprobación de los estatutos, fueron varias las intervenciones que cuestionaron dicho planteamiento. El diputado del PNV por Vizcaya, José Horn Areilza, en representación de la Minoría V-N hizo un planteamiento, en el que "se corrige esto, haciendo referencia a las dos terceras partes de los electores inscritos en el censo, pero que tomen parte activa en la votación" ${ }^{30}$, ya que de otra manera se dejaría en manos de los no votantes la decisión de aprobación o no del Estatuto. Sobre este mismo tema del porcentaje de votos necesarios para conceder la autonomía a una región, se produjeron diferentes planteamientos, muchos de ellos propugnando el sistema ordinario de la mayoría, pero en opinión de la Comisión, expresada en este caso por uno de sus miembros, el radical Ricardo Samper lbáñez,

"La Comisión ha considerado que cuando se trata de la autonomía de la región, que ha de asumir el ejercicio de graves e importantes jurisdicciones, no basta la voluntad mayoritaria, porque una mayoria puede producirse artificialmente, en momentos de emoción, después de una intensa propaganda, [...], y por eso no le basta a la Comisión con esa mayoria [...] sino con las dos terceras partes de los electores que componen el censo electoral de la región, porque esa será la garantía de que la región quiere la autonomía y la merece" ${ }^{31}$.

El proyecto constitucional presentaba tres fases para la aprobación de los estatutos: primero, que solicitasen el Estatuto la mayoría de los Ayuntamientos de la comarca o por lo menos, aquellos que representasen la voluntad de las dos terceras partes de electores de la región; segundo, que lo votasen las dos terceras partes de electores que figurasen en el Censo y tercero, que lo aprobase el Parlamento. Con relación a la segunda fase, incluida en el citado artículo 12, el parlamentario nacionalista José Antonio Aguirre, mostró su desacuerdo con el hecho de que hubiesen de pasar 5 años para presentar una nueva propuesta dado caso que el plebiscito fuera negativo.

Delimitadas en los artículos 14 y 15 las materias de exclusiva competencia del Estado en legislación y ejecución, todos los demás extremos 
de la acción política podían quedar en la esfera de las regiones autónomas, si bien explicitándolas en el correspondiente estatuto o en leyes especiales (arts. 16 a 22). Algunos representantes de la Minoría vasco-navarra presentaron enmiendas a favor de un régimen de cultos autónomo para las regiones y la facultad de éstas de establecer directamente relaciones concordatarias con la Santa Sede ${ }^{32}$. Alcanzó en este punto gran notoriedad la enmienda del diputado Juarros.

Haciendo nuevamente uso de la teoría del pactismo, recordó el diputado Leizaola cómo fue la vía del pacto la que sirvió para unir los territorios de Castilla y las provincias vascas, y que como consecuencia de ello habian sido siempre las provincias vascas las que habían cedido en los temas de litigio con el Estado, solicitando que, aprovechando ese momento histórico que significaba el estar todos reunidos para crear una nueva Constitución, se reconociesen a las regiones en general y al País Vasco en particular asumir lo que se denominan "residuos", es decir aquellas facultades que no aparecen otorgadas, bien en la Constitución bien en los pactos accesorios a éstas.

Entre las enmiendas presentadas por los parlamentarios de la Minoría vasco-navarra a estos artículos, citaremos la presentada por Joaquín Beunza al artículo 13, a favor de que las regiones autónomas pudieran federarse, que no fue aceptada. Pero fue el artículo 14 en el que se mostró más combativa la Minoría vasco-navarra, que sistemáticamente trató de excluir de entre las competencias exclusivas del Estado, las relaciones entre la Iglesia y el Estado y el régimen de cultos. El voto particular de Leizaola ${ }^{33}$ trataba directamente de suprinir el número 2 (régimen de cultos) del artículo 14, e incluir en el 15 las relaciones con las iglesias en las regiones que recabasen para sí esta facultad. De esta manera el proyecto de Estatuto de Estella que reivindicaba dicha competencia, tendría viabilidad en ese punto. El voto no fue tomado en consideración por la Cámara, que volvió a rechazar una tras otra las tres enmiendas presentadas con la misma intención por la Minoría vasco-navarra. En la primera se trataba

${ }_{32}$ Según la enmienda principal al art. 14 serian materias potestativas de las regiones autónomas: «Relaciones con las iglesias y régimen de cultos en las regiones que recaben para sí esta facultad, para cuyo caso se reserva el Estado el amparo en última instancia de la libertad de conciencia para que nadie pueda ser obligado a abrazar, contra su voluntad, una religión determinada, ni dificultado en el ejercicio de la suya, sin que el hecho de profesar una cualquiera o el de no profesar ninguna impida el acceso, en tales regiones a las funciones públicas; pudiendo también oponer su veto a la regulación pública de la vida religiosa que infringiere estas garantías" Apéndice 10 al D. de S. n. 24 de 20 de agosto de 1931.

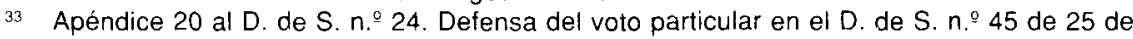
septiembre de 1931, págs. 1204-1206. 
de añadir al artículo 14, "sin perjuicio de los que el parlamento acuerde al discutir los Estatutos regionales", con lo que volvían a abrírsele las puertas al Estatuto de Estella. La segunda, defendida por el canónigo Antonio Pildain Zapiain pedia que se le añadiese al párrafo segundo «... salvo cuando la libertad religiosa de las regiones autónomas exigiere que se les reconozca a ellas esa facultad". El último intento corrió a cargo de Rafael Picavea que trató de defender una enmienda que coincidía totalmente con la anterior, aduciendo su condición de liberal.

El acuerdo entre el PSOE y AR permitió la introducción del concepto Estado integral con la vista puesta en una rápida solución de la cuestión catalana y pensando en el Estado unitario, ni centralista ni federal, compatible con la autonomía de los Municipios y de las Regiones.

Tras arduas negociaciones y a propuesta de J. Besteiro, presidente de las Cortes, se concretó un dictamen de armonía, dejando un amplio margen a la discusión particular de cada Estatuto. A cambio consiguieron los socialistas que los Estatutos fueran discutidos artículo por artículo en las Cortes y que sólo entrasen en vigor con su aprobación, con lo que se evitaba la cesión de soberania a los entes regionales.

A raíz de esta situación de rechazo de la cláusula concordataria, el 7 de octubre los diputados derechistas vascos se reunieron en Madrid con el fin de tomar una decisión. Aguirre lo plantearía sin ambages, "no hay mas que dos caminos a seguir: uno, mantener la bandera llegando incluso a la violencia, a la lucha abierta; otro, conseguir lo que se pueda como medio de ir avanzando en la conquista de nuestras libertades perdidas". Según Aguirre el nacionalismo confesional no podía aprobar una Constitución atentatoria de la conciencia religiosa, pero si aprovechar de ella el mayor número de bienes posibles para su pueblo, decidiendo finalmente que se siguiese en la defensa de cuantas aspiraciones autonómicas pudiesen arrancarse de la Constitución ${ }^{34}$.

Con el artículo 44 discutido los días 6 y 7 de octubre, en el que se trataba el tema de la admisión de la expropiación forzosa de la propiedad privada, con o sin indemnización por causa de utilidad publica, y entre graves disensiones del colectivo parlamentario, el católico navarro Rafael Aizpún expuso el criterio de la M.V-N sobre los artículos referentes a la propiedad privada. Avisó del voto negativo de su Minoría al dictamen presentado, pues aún no recogiendo éste en su redacción el carácter forzoso

34 LANDA, Carmelo: Jesús M. ㄹeizaola: vida, obras y acción política de un nacionalista vasco (1896-1937). Fundación Sabino Arana, Bilbao, 1995, pág. 313-314. 
de la socialización, la amparaba como principio constitucional y mantenía el derecho del Estado a expropiar sin indemnizaciones, a la nacionalización de los servicios públicos, y las explotaciones que afectasen al interés nacional. Afirmó «no podemos votar esta propuesta de la Comisión Constitucional, porque en ella se establece el derecho de expropiar sin indemnización» ${ }^{35}$. Un tercer matiz de queja hace referencia a la ambigüedad en la redacción de determinados párrafos, en concreto cuando se hace referencia al deber de nacionalizar en el menor plazo posible «los servicios públicos y las explotaciones que afecten a interés nacional" ${ }^{36}$, echando de menos un criterio más concreto, que las definiese y las determinase de una manera menos vaga.

El 8 de octubre de 1931 comenzó a discutirse en las Cortes el articulo 24 de la Constitución, dedicado a las relaciones Iglesia-Estado. Los artículos 3, 24 y 25 dieron para un intenso juego del 10 al 14 de octubre. Así mientras en el artículo 3 se establecía la aconfesionalidad del Estado, en el 24 y 25 -que serían el 26 y 27 de la Constitución- se delimitaban los derechos religiosos de los españoles y la competencia del poder público en la salvaguarda de tales derechos. Se igualaba a todas las confesiones religiosas como asociaciones sometidas a las leyes generales de la nación, no permitiéndose al Estado el prestar ningún tipo de ayuda económica. Cualquier tipo de manifestación religiosa se limitaba al interior de los templos, garantizándose en todo caso la privacidad del derecho a practicar o no alguna religión.

Como se puede imaginar, el tema desencadenó todo tipo de pasiones y posicionamientos en la opinión pública y lógicamente muchas de ellas se tradujeron en solicitudes a la Mesa del Congreso de peticiones populares tanto en favor como en contra del texto de la Comisión, así como numerosas enmiendas que proponían desde el reconocimiento de los derechos eclesiásticos (partidos derechistas), al refuerzo de las medidas anticlericales (socialistas, radicales-socialistas), pasando por las moderadas (PRR y AR) que buscaban facilitar el consenso, renunciando a aplicar o a modificar al menos algunas de las medidas de los artículos inicialmente propuestos, como sugirió el ministro de Justicia, el socialista Fernando de los Ríos, ante la intransigencia de ambos bloques.

El aperitivo sobre lo que habría de pasar en la sesión del día 13 lo ofreció el portavoz de la M. V-N Beunza unos días antes al tratar de forma

\footnotetext{
D. de S. n. 950 de 6 de octubre de 1931, pág. 1443.

D. de S. n. ${ }^{0} 50$ de 6 de octubre de 1931, pág. 1443.
} 
global todo lo referente a las cuestiones religiosas, economía incluida, respecto a la cual se argumenta la petición - a modo de derecho de la Iglecia- de que se le siguiese pasando la asignación correspondiente a culto y clero, algo a lo que parecen no estar dispuestos la mayoría de los parlamentarios. Los propios componentes del Gobierno, a título particular, no escapaban a esta polémica pues la existencia de católicos en el equipo ministerial planteaba problemas de conciencia a los mismos y el propio jefe de Gobierno, Niceto Alcalá-Zamora se opuso contundentemente a las medidas contra las ordenes religiosas, abriéndose la posibilidad de una crisis gubernamental. En este punto surgió la figura de Manuel Azaña, líder de AR, quien defendió las tesis moderadas que habrían de imponerse: una regulación de las órdenes religiosas y la disolución sólo de aquellas que fueran "peligrosas para la República". Pese a que sus propuestas de prohibir ejercer la enseñanza a los religiosos o de que se diera poder a las Cortes para fijar la disolución de las ordenes fueron medidas ciertamente anticlericales, dado el ambiente político del momento, ha sido considerado por algunos como una medida conciliatoria, e incluso «a favor de la lglesias ${ }^{37}$.

La sesión del día 13 de octubre de 1931 fue decisiva para la aprobación de los artículos donde se reflejaría el ordenamiento de las mencionadas cuestiones religiosas, siendo pródiga en intervenciones de los parlamentarios de la Minoría vasco-navarra: Beunza, Pildain, Leizaola en varias ocasiones, Oreja, Oriol, Domínguez Arévalo. Respecto al artículo $3 .^{\circ} \mathrm{del}$ proyecto constitucional, Beunza reiteró su desacuerdo con el cambio de "pasar de la religión católica como religión oficial del Estado a que el Es tado careciese de religión» ${ }^{38}$, quedando la redacción final: «El Estado español no tiene religión oficial' " ${ }^{39}$, lo que fue criticada duramente por el diputado Pildain al afirmar, entre otras cosas, que tal enunciado no se podía encontrar en ninguna otra Constitución europea.

La minoría socialista acordó adherirse por 59 contra 32 al nuevo art. 26 modificado con las sugerencias que había hecho Manuel Azaña. Reunida la Comisión de la Constitución sin la presencia de Gil Robles y Leizaola por no haber sido avisados, ésta incluyó las modificaciones propuestas, volviendo a reunirse la Cámara a las doce y diez de la noche, presentándose la tercera redacción del art. 26. Las minorías agraria y vasco-navarra

\footnotetext{
37 Raguer, H.: “España ha dejado de ser católica: La politica religiosa de Azaña, en Historia contemporánea, 6,1991 , pág. 150.

${ }^{38}$ D. de S..$^{9} 55$ de 13 de octubre de 1931 , pág. 1648

39 D. de S. n. 55 de 13 de octubre de 1931, pág. 1654
} 
intentaron la obstrucción parlamentara para demostrar al pais su oposición al artículo que se iba a aprobar, si bien los intentos no lograron su objetivo.

Respecto al artículo 24 referido a la regulación, a la disolución de las Órdenes religiosas, Leizaola recurrió a la defensa de las personas que han dedicado su vida a la religión, "con mayor heroísmo, con mayor generosidad para sacrificarse por sus semejantes" ${ }^{40}$ al privarles con la nueva legislación de sus derechos civiles y políticos. Para ejemplificar con problemáticas concretas de esta situación, recurrió a la mención de los misioneros y de sus actuaciones por todo el mundo, y como esa labor se podría identificar con la de embajadores de la cultura española. Sobre todo se destaca el caso de América, tierra ésta donde habian dejado especialmente su influencia y habian manteniendo y ayudando a mantener la lengua castellana frente al progresivo imperialismo norteamericano.

Buscando la contradicción entre las filas socialistas, cita Leizaola ejemplos de multitud de países donde gobernaban los socialistas y donde sí se había respetado a las órdenes religicsas, incluso, señala, añadiendo mejoras, frente a un proyecto español que no permitía mostrar el catolicismo y que alababa y toleraba el anticlericalismo. Como nuevo argumento y haciendo referencia a las formas, se critican las prisas, la premura de tiempo para la realización de algo tan importante como un proyecto constitucional (20 días), criticando asimismo el no plantearse otras soluciones y admitiendo que desde su grupo se estaría dispuesto, como medida de buena voluntad, a asumir una reducción del número de religiosos.

Sobre el tema de las posesiones de las órdenes religiosas, se defendió por parte de los miembros de la Minoría V-N que muchas de ellas eran recompras de las órdenes religiosas tras la desamortización. $Y$ una curiosa reflexión no carente de certeza en cuanto a los edificios considerados como bienes culturales. Mientras la mayoría de los caídos en manos particulares estaban hundidos, los que estaban en manos religiosas, en buena parte se encontrarían restaurados, (Silos, San Millán, etc.).Para la defensa de las órdenes religiosas se recurre como argumentos de peso, por un lado a la importante labor docente y formadora en oficios que venían realizando muchas de ellas y especialmente los jesuitas, y sin cuyo concurso, pese al esfuerzo que pudiese realizar el Estado, serían muchos los privados de esa formación tan necesaria, solicitando de paso, un mismo régimen y derechos para la enseñanza religiosa y para la oficial,

40) D. de S. n. 55 de 13 de octubre de 1931, pág. 1675. 
sobre todo, en los tiempos tan difíciles en lo económico que se vivían en el momento. Por otro lado, algo similar se argumenta como labor social de asistencia a los menos favorecidos que realizaban las órdenes religiosas, con la atención prestada en sus centros. "Si la República ha de vivir, si queréis que dure y se consolide, ha de ser para todos; han de poder vivir dentro de ella los católicos lo mismo que los que no lo desean" ${ }^{41}$.

Comenzó la sesión de la tarde del día 13 de octubre con la votación del art. 3 según el cual "el Estado Español no tiene religión oficial" ${ }^{42}$. La mayor parte de las enmiendas y votos particulares al citado art. 3 fueron retirados ya que la nueva redacción parecía satisfacer a casi toda la Cámara. Por ejemplo, el canónico Antonio Pildain había presentado a la Cámara una enmienda redactada en los siguientes términos: «El Estado español reconoce a la Iglesia católica su personalidad jurídica de sociedad perfecta" "43, aprovechando la ocasión para plantear una amenaza de guerra civil y condicionar así el ánimo de la Cámara:

"Sr. Presidente, a mi me incumbe el deber de hacer constar que, según la doctrina católica, ante una ley injusta caben estas tres posiciones perfectamente lícitas: primera, la de la resistencia pasiva; segunda, la de la resistencia activa legal, y tercera la resistencia activa a mano armada.(Grandes protestas. Muchos señores diputados increpan al orador. Algunos Srs Diputados de la minoria radical-socialista pronuncian palabras que no se perciben, dirigiéndose a los de la minoría socialista que son contestadas por éstos. El Sr. Presidente agita la campanilla reclamando orden) ${ }^{44}$.

Ante el revuelo organizado matizó:

"Otra cosa es la insurrección contra el Poder constituido, que es lo que prohibe la Iglesia" 45 .

Completó su crítica haciendo referencia a que mientras en esos mismos momentos había otro tipo de sociedades que atacaban continua y directamente al Gobierno y no se tomaban medidas contra ellas, sí se arremetía contra los jesuitas y otras órdenes religiosas. La enmienda fue rechazada, después de ruidosas manifestaciones en contra.

41 D. de S. n. 54 de 10 de octubre de 1931, pág. 1635.

42 Apéndice 3 al D. de S. n. 35 de 10 de septiembre de 1931.

43 D. de S. $n .^{9} 55$ de 13 de octubre de 1931.

44 D. de S. n. 95 de 13 de octubre de 1931, pág. 1707

45 D. de S. n. ${ }^{\circ} 55$ de 13 de octubre de 1931, pág. 1707 
Ante una situación tan tensa y llena de agresivas intervenciones verbales, la intervención mediadora de Manuel Azaña, jefe de Acción Republicana y ministro de la Guerra, dio sus frutos y los socialistas recapitularon su posición. La nueva redacción del texto recogía las propuestas del centro-izquierda, y a eso de las siete de la mañana del día 14 comenzó la votación. Algunos diputados salieron del salón de sesiones para no verse obligados a emitir su voto. El resultado de la votación fue de 175 a favor frente a 59 en contra del articulado religioso.

La aprobación de estos artículos trajo consigo una considerable agitación en el país. Desde el bando de católicos, agrarios y vasco-navarros anunciaron al día siguiente su retirada del parlamento (42 en total), en protesta por la actitud de la mayoría, haciendo público en Pamplona el día 17 un manifiesto en el que se resumían los argumentos de la derecha para combatir el conjunto de las reformas aprobadas por las Cortes Constituyentes. Paradójicamente, también había sectores de izquierdas que, como los radical-socialistas, rechazaban el articulado religioso de la Constitución, considerándola demasiado favorable a los intereses eclesiásticos.

Tal y como señala Meer Lecha-Marzo ${ }^{46}$, la votación del artículo 26 puso de manifiesto la no-unanimidad en la política religiosa de las fuerzas que componian el Gobierno provisional y significó la primera crisis importante entre los dirigentes de la República.

Una de las consecuencias más significativas de todo este proceso de enfrentamiento y desgaste fue la dimisión como miembros del Gobierno provisional el mismo día 14 del presidente del mismo Alcalá-Zamora, y del ministro de Gobernación Miguel Maura, alegando razones de conciencia. En consecuencia Besteiro, presidente de las Cortes, encomendó a Manuel Azaña el día 15, la dirección y reorganización del gabinete ministerial. El día 17 Azaña expuso en el Congreso un programa de actuación gubernamental que dejaba definitivamente atrás la etapa provisional y contemplaba las grandes líneas de un ambicioso plan de reformas.

Superado el tema religioso, las sesiones parlamentarias continuaron en un ambiente de mayor armonía entre los grupos gubernamentales, mientras la voluntaria ausencia de agrarios y vasco-navarros reducía a su mínima expresión a las fuerzas de la oposición.

46 Meer Lecha-Marzo. Op. cit., pág. 193. 
Continuaron los debates correspondientes a derechos y deberes de los españoles (arts. 25 a 50). Enrique de Francisco Gómez, parlamentario del PSOE por Guipúzcoa, en representación de la minoría socialista, tras defender la no pasionalidad en el análisis de los temas, y ante los continuos ruegos de los catalanes de que se hiciesen las cosas de manera que no se prejuzgase su Estatuto, sostuvo lo contrario, afirmando,

"yo digo algo que nos interesa mucho más: importa mucho, muchisimo que la Constitución no esté prejuzgada por los Estatutos" ${ }^{47}$.

Es decir, el claro planteamiento de los socialistas y republicanos era que los estatutos habrían de ser siempre consecuencia de la Constitución y no al revés, achacando a los catalanes el no examinar con mayor amplitud de miras las posibles consecuencias que algunas de sus peticiones podian originar en otras regiones. Sería el caso de la enseñanza y las consecuencias diferentes que podría tener en cada territorio

"un precepto constitucional en el cual se reconozca sin reservas a la región el derecho de organizar su enseñanza. [...]. Dar enseñanza en vascuence, constituye para Vasconia, incluida Navarra, una verdadera tragedia; porque en Vasconia, fuera de la zona rural de los pueblos de Vizcaya y de Guipúzcoa, fuera de la parte pequeñisima de Alava lindante con Vizcaya y fuera de un cierto número de pueblos de Navarra que lindan con el Pirineo, en el resto del país no se habla más que castellano" ${ }^{48}$.

Hizo igualmente su aportación al tema del regionalismo, al independentismo, desde la perspectiva socialista, al señalar que "Nosotros hablamos de autonomía regional y, al hablar de esta autonomía, nos hemos enfrentado en la región vasconavarra con los que representaban el criterio nacionalista independiente" ${ }^{49}$, afirmando eso sí, no temer ningún planteamiento, ni siquiera si alguna región era independencia plena lo que legitimamente postulaba en derecho. Aún asi deja claro que el planteamiento socialista para la región vasconavarra era el de plena autonomía, reconociendo la plena soberanía del Estado sobre el territorio.

Incidiendo en el tema de la educación, concreta la posición socialista en un "queremos que la enseñanza sea para el alumno y no el alumno víctima de la enseñanza" ${ }^{50}$, ejemplificando con las escuelas de castellano

\footnotetext{
47 D. de S. n. ${ }^{9} 61$ de 22 de octubre de 1931, pág. 1881.

48 D. de S. n. ${ }^{\circ} 61$ de 22 de octubre de 1931, pág. 1882

D. de S. n. 61 de 22 de octubre de 1931, pág. 1881

D. de S. n. ${ }^{\circ} 61$ de 22 de octubre de 1931, pág. 1883.
} 
que en el interior de Guipúzcoa ayudan a quien desea aprender la lengua de Cervantes, pensando sobre todo en los que salen, emigran hacia otras tierras, América principalmente, con los graves problemas añadidos que les ocasiona el imperfecto conocimiento del castellano. Ofertas estas que, aseguró, eran brutalmente perseguidas por los reaccionarios.

Dentro de la discusión de los artículos dedicados a las Cortes (arts. 51 a 66) se incluía entre otros el tema del sistema parlamentario que habría de adoptar la República. La posición del grupo socialista fue defendida por el parlamentario vizcaíno Indalecio Prieto, quien en una completa intervención de alta oratoria se opuso al bicameralismo, ya que

"la historia de todas las democracias mundiales es una pugna constante con los fueros de las llamadas Cámaras Altas, que están siempre, no ya frenando, sino dificultando la plasmación de las aspiraciones democráticas que el pueblo quiere darse por mediación de sus delegados directos" ${ }^{51}$.

Se defiende así el valor supremo de la decisión del pueblo a la hora de elegir a sus representantes, y no a las Corporaciones que son las tradicionales ocuparites de las Cámaras Altas. Como riesgo de esta segunda Cámara se apunta por parte de Prieto a la politización de las instituciones culturales y a la injerencia del caciquismo en la misma.

En el título que se ocupaba de la Hacienda Pública (arts. 107 al 120), una de las discusiones más enconadas fue la referida a! control o no por parte del Tribunal de Cuentas de la República, dependiente directamente de las Cortes, de las cuentas regionales (art. 116). Las diversas regiones aspirantes a la autonomía, defendian el principio de que no podía haber una plena autonomía si se le habian de fiscalizar las cuentas a la región autónoma. En el caso navarro, coinciden diputados de grupos distintos con Emilio Azarola (Radical) y Mariano Ansó (Republicano autónomo) en pedir una legislación especial para su territorio, dadas las peculiaridades históricas que habían caracterizado la misma a lo largo de la Historia ${ }^{52}$. Su petición fue denegada.

Una intervención que hubiese agradado a los ausentes parlamentarios de la Minoría parlamentaria vasco-ravarra fue la que realizó Indalecio Prieto en calidad de diputado socialista vizcaino, no de Ministro, según sus propias palabras, para defender la estructura, contenido y furición del tradicional Concierto económico que venía rigiendo las relaciones fiscales

51 D. de S. n. 963 de 27 de octubre de 1931, pág. 1959.

52 D. de S. n. 80 de 25 de noviembre cie 1931 , pág. 2628. 
entre el Estado y las provincias vascongadas y que con alguna de las nuevas propuestas realizadas por la nueva Constitución, corría peligro de sufrir una grave alteración de su estructura tradicional ${ }^{53}$. Las sociedades anónimas domiciliadas en territorio foral tributaban a las Diputaciones por aquella parte de sus beneficios obtenidos dentro del territorio foral, y rendían sus tributos al Estado por aquella parte de sus negocios por la cual obtenian beneficios en el resto del territorio nacional. La crítica de Prieto era que el obligar a que las contribuciones directas de las industrias domiciliadas en el territorio autónomo, hubieran de ir forzosamente a rendir al Estado equivalía a destruir "la savia, la sustancia, el nervio económico de todo régimen de autonomía" ${ }^{54}$.

El 1 de diciembre se daba fin al debate, y el día nueve se procedió a la votación y aprobación definitiva del proyecto de Constitución. Previamente a la votación se hizo referencia a una serie de Sres. Diputados -17que no habiendo podido acudir a la misma por causas ajenas a su voluntad, solicitaban que constase su voto favorable. De los 466 diputados que habían prometido su cargo en las Cortes, tomaron parte en la votación 368 y ese mismo número voto sí ${ }^{55}$. A ellos se sumaron las 17 adhesiones de diputados ausentes.

Como se deduce de lo anterior, el nivel de participación de los parlamentarios de las provincias vasco-navarras de las diversas ideologías no fue pequeño. Unos, los integrados en el grupo Minoría $V-N$, con una continua y persistente obsesión por dejar plasmadas en la nueva Carta Magna su concepto de sociedad religiosa por una parte y la defensa de un alto porcentaje de autonomía para su territorio por otro. Frente a ellos los socialistas y republicanos de izquierda mantuvieron la postura de primar los valores generales del nuevo régimen republicano frente a los intereses partidistas de una región. En los años posteriores la disolución de la Minoria $\mathrm{V}-\mathrm{N}$ haría que los nacionalistas se acercaran a las posturas de republicanos y socialistas con la finalidad de hacer realidad su deseo de poseer un Estatuto de autonomía, tal y como posibilitaba la Constitución, algo que lograrían con el apoyo socialista en 1936. Los tradicionalistas por su parte, se apartarían progresivamente de los presupuestos constitucionales hasta desembocar en los medios violentos como medio de implantación de sus aspiraciones.

\footnotetext{
53 D. de S. n. 80 de 25 de noviembre de 1931, pág. 2636

54 D. de $S . n{ }^{9} 80$ de 25 de noviembre de 1931 , pág. 2636.

55 D. de S. n. 98 de 9 de diciembre de 1931, pág. 2910.
} 